\title{
Molecular mobility changes after high-temperature, short-time pasteurization: An extended time-domain nuclear magnetic resonance screening of ewe milk
}

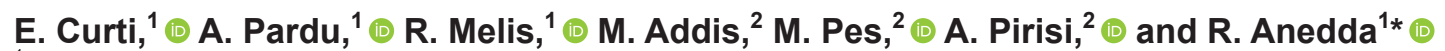 \\ ${ }^{1}$ Porto Conte Ricerche s.r.l., S.P. 55 Porto Conte-Capo Caccia, Km. 8,400 Loc. Tramariglio, 07041 Alghero (SS), Italy \\ ${ }^{2}$ AGRIS Sardegna (Agricultural Research Agency of Sardinia), Loc. Bonassai, 07040 Olmedo, Italy
}

\begin{abstract}
This study presents an extensive investigation on the effect of pasteurization on raw whole ewe milk. Milk samples have been analyzed, throughout lactation (from February to July), by time-domain nuclear magnetic resonance (TD-NMR), collecting the characteristic TDNMR relaxation parameters, proton longitudinal and transverse relaxation times $\left({ }^{1} \mathrm{H} \mathrm{T}_{1}\right.$ and $\left.\mathrm{T}_{2}\right)$. Collected data aim at integrating previous NMR works, mainly focusing on dairy model systems (casein and whey proteins solutions and gels, reconstituted skim milk) and cheese, with specific reference to the effect of heat treatments. Whole ewe milk, from a single flock (Sarda sheep breed), was daily analyzed both as untreated (raw) and heat treated with a laboratory-scaled hightemperature, short-time treatment $\left(72^{\circ} \mathrm{C}\right.$ for 15 and 20 s). Moreover, molecular dynamics in milk were investigated by TD-NMR in different periods of lactation for the first time. As a consequence of high-temperature short-time treatment, ${ }^{1} \mathrm{H} \mathrm{T}_{1}$ and $\mathrm{T}_{2}$ consistently shifted to lower values with respect to raw counterparts. Statistical analysis indicated a significant decrease of $\mathrm{T}_{2}$ in treated samples, to an extent dependent on the heat treatment duration. A subset of dedicated experiments demonstrated that the observed $\mathrm{T}_{2}$ shift is largely ascribable to protein molecular rearrangements and, to a lesser extent, to the interaction of fat globules with proteins or other nonfat components (or both). In light of the crucial importance of detecting the application of a heat treatment to milk, the results reported here suggest TD-NMR relaxation parameters were able to describe heat-induced changes in molecular dynamics and interactions of milk components in a water-rich environment. The use of TD-NMR can be considered a
\end{abstract}

Received September 20, 2019.

Accepted June 29, 2020.

*Corresponding author: anedda@portocontericerche.it potential suitable technique for quality control and assurance practices in the dairy industry. Upon statistical validation of methods, the application of TD-NMR in the dairy industry would take advantage of its low cost, reliability, and robustness.

Key words: sheep milk, time-domain nuclear magnetic resonance, heat treatment

\section{INTRODUCTION}

The application of heat treatments to milk is widely exploited currently, especially at an industrial level. Heat is applied to make milk suitable for human consumption and cheese/dairy production. Heat treatments primarily aim at destroying pathogenic flora and reduce undesirable gas and off-flavor-forming organisms in raw milk.

Heating conditions are usually optimized, with proper temperature and duration combinations, to ensure a minimized alteration of milk molecular properties. Nevertheless, depending on the applied heat treatment, several physico-chemical modifications are known to occur, inducing undesirable alterations in the functionality of specific milk components. Often, such molecular changes lead to an alteration of the cheesemaking properties of milk (Singh and Waungana, 2001). Heat treatments have been shown to cause a progressive monomerization and denaturation of whey proteins (deWit and Klarenbeek, 1984; Fox et al., 2015) and enzyme inactivation (Piga et al., 2013). Moreover, heat treatments promote interactions between serum proteins and membrane of fat globules (Corredig and Dalgleish, 1996), as well as between serum proteins and casein micelles (Fox et al., 2015). The abovementioned molecular rearrangements can result in sensible modifications of sensory and nutritional properties of treated milk and of the corresponding dairy products (Buchin et al., 1998; Mendia et al., 1999; Morales et al., 2000; Caboni et al., 2019).

Time-domain nuclear magnetic resonance (TDNMR) is known for its ability to monitor complex 
molecular changes occurring in several food systems (van Duynhoven et al., 2010). Useful applications of TD-NMR for the dairy industry have been developed. Time-domain nuclear magnetic resonance has been exploited mostly on model systems and reconstituted skim milk so far. For example, the effect of heat treatment $\left(60-80^{\circ} \mathrm{C}\right.$, Lambelet et al., 1989, 1992) and acidification (Mariette et al., 1993) on skim milk could be described in terms of changes in molecular mobility, with reference to the transverse relaxation time constant $\left(\mathrm{T}_{2}\right)$. Interestingly, curd syneresis can be monitored and described by NMR relaxation parameters, which turned out to be significantly affected by heat treatments (Tellier et al., 1993; Calvo and Balcones, 2000; Hansen et al., 2010; Curti et al., 2019). Monitoring the efficacy of heat treatments on milk is required for quality assurance and control in the dairy industry. The established official method for controlling milk pasteurization measures the residual activity of alkaline phosphatase (European Commission, 2006; ISO, 2013). However, alkaline phosphatase testing exhibits some criticalities and its reliability has been questioned (Scintu et al., 2000; Raynal-Ljutovac et al., 2007; Moatsou, 2010; Rankin et al., 2010). Preliminary investigations carried out in our laboratory showed the ability of magnetic resonance to detect heat-induced changes in milk, curd, and cheese (Mulas et al., 2013; Curti et al., 2019). The present work complements the abovementioned findings on a much larger data set by analyzing the effects of a laboratory-scale HTST pasteurization treatment on ewe milk, in different periods of lactation. The potential of TD-NMR in detecting heat-promoted molecular modifications, regardless of season and the associated compositional variability of milk, is described here. Conclusions are drawn by comparing raw milk samples and their HTST-treated counterparts, on a daily basis, from February to July and based on an additional subset of measurements aimed at understanding the influence of other factors such as $\mathrm{pH}$, water evaporation, skimming, milk fat homogenization, and intrasample variability.

\section{MATERIALS AND METHODS}

\section{Sheep Milk Supply}

Fresh raw whole ewe milk was obtained from a single local flock (Sarda sheep breed; Agris Sardegna, Sassari, Italy) on a daily basis during 6 mo of lactation (February-July). Milk was transported to the laboratories in a plastic (polyethylene terephthalate) bottle, stored in refrigerator at $6^{\circ} \mathrm{C}$, and analyzed within $12 \mathrm{~h}$ from milking.

\section{Milk Sampling and Heat Treatment}

Following gentle agitation, a batch of milk $(\approx 50$ $\mathrm{mL}$ ) was extracted from the bottle and 3 aliquots were directly pipetted into 3 NMR glass tubes (10 mm diameter, $180 \mathrm{~mm}$ height, Bruker Biospin, Milan, Italy; Figure 1). The volume in each NMR tube was optimized to $680 \mu \mathrm{L}$ to ensure full immersion of the sample in the homogeneous magnetic field region of the spectrometer magnet. The NMR tubes were equilibrated at $25^{\circ} \mathrm{C}$ (Elma, Elmasonic S 30 H, Berlin, Germany) for 10 min before analysis.

One of the 3 samples was analyzed untreated (raw $=\mathbf{R}$ ), whereas the remaining 2 samples were analyzed after a heat treatment protocol simulating the HTST procedure (heat treated $=\mathbf{H T}$ ). Two different heat treatments were tested: $72^{\circ} \mathrm{C}$ for $15 \mathrm{~s}(\mathbf{H T 1 5})$ and $72^{\circ} \mathrm{C}$ for $20 \mathrm{~s}$ (HT20), consisting of a 2-step time- and temperature-controlled heating process (digital stainlesssteel thermoprobe, VWR Collection, Milano, Italy). To perform the HTST treatment, each sample-loaded NMR tube was immersed in a water bath at $85^{\circ} \mathrm{C}$ (first step), with continuous manual agitation, to heat milk from room temperature $\left(23^{\circ} \mathrm{C}\right.$ ) to $72^{\circ} \mathrm{C}$ (required time $=5 \mathrm{~s}$, based on preliminary experiments) and immediately transferred into a second water bath at $72^{\circ} \mathrm{C}$ (second step), for 10 (HT15, i.e., $5+10$ s) or 15 (HT20, i.e., $5+15 \mathrm{~s}$ ) s. Immediately after the heat treatment, HT samples were quench-cooled in an ice-water basin (required time $=10 \mathrm{~s}$ to cool down to about $15^{\circ} \mathrm{C}$, based on previous trials) with continuous manual agitation. The complete experimental plan included at least 3 and up to 6 milk batches (i.e., analysis of R, HT15, and HT20 per batch) on a daily basis (Figure 1), resulting in $\sim 1,500$ analyses overall. Heat treatments and acquisition of replicates of R, HT15, and HT20 samples were randomized in the daily schedule.

\section{Measurement of $\mathrm{pH}$}

Milk $\mathrm{pH}$ was measured with a temperature probeequipped $\mathrm{pH}$ meter ( $\mathrm{pH}$ 210, Hanna Instruments Italy s.r.l., Padova, Italy). The $\mathrm{pH}$ was checked as the milk was received in the laboratory (after equilibration to $25^{\circ} \mathrm{C}$ ) and before each analysis on raw milk batches progressively extracted from the bottle throughout the day.

\section{Milk Composition}

Samples of raw whole milk were analyzed for fat, protein, casein, lactose content, and SCC using a Milkoscan FT+ (Foss, Hillerød, Denmark). 


\section{${ }^{1} H T D-N M R$}

The ${ }^{1} \mathrm{H} \mathrm{T}_{1}$ longitudinal (inversion recovery sequence; recycle delay $7 \mathrm{~s}$, log-spaced interpulse range 1-12,000 $\mathrm{ms}, 20$ data points) and ${ }^{1} \mathrm{H} \mathrm{T}_{2}$ transverse (Carr-PurcellMeiboom-Gill pulse sequence; recycle delay $7 \mathrm{~s}$, interpulse spacing $0.0567 \mathrm{~ms}, 8,000$ data points) relaxation curves were obtained with a low-field NMR spectrometer $(20 \mathrm{MHz}$, the miniSpec, Bruker Biospin, Milan, Italy), operating at $25.0 \pm 0.1^{\circ} \mathrm{C}$ (JULABO, F25-ED, Milan, Italy).

\section{Fitting of Experimental ${ }^{1} \mathrm{H}$ TD-NMR Data}

The relaxation curves were fitted with the CONTIN algorithm (Provencher, 1982; software provided by Bruker, Milan, Italy) to obtain quasicontinuous distributions of $\mathrm{T}_{1}$ (400 points; range: $1-5,000 \mathrm{~ms}$ ) and $\mathrm{T}_{2}$ (400 points; range: $1-500 \mathrm{~ms}$ ). The distributions were then fitted with a Beta equation ("BetaAmp," Equation [1], where $\mathrm{a}_{0}=$ amplitude, $\mathrm{a}_{1}=$ center, $\mathrm{a}_{2}=$ width, $\mathrm{a}_{3}=$ shape 1 , and $\mathrm{a}_{4}=$ shape 2 ) that well represents the observed shape (Table Curve software, trial version, Systat, San Jose, CA):

$$
(x)=
$$$$
\frac{a_{0} \times\left(\frac{x-a_{1}+\frac{a_{2}\left(a_{3}-1\right)}{a_{3}+a_{4}-2}}{a_{2}}\right)^{a_{3}-1} \times\left(1-\frac{x-a_{1}+\frac{a_{2}\left(a_{3}-1\right)}{a_{3}+a_{4}-2}}{a_{2}}\right)^{a_{4}-1}}{\left(\frac{a_{3}-1}{a_{3}+a_{4}-2}\right)^{a_{3}-1} \times\left(\frac{a_{4}-1}{a_{3}+a_{4}-2}\right)^{a_{4}-1}} .
$$

Characteristic $T_{1}$ and $T_{2}$ relaxation times (ms), representative of the maximum of each distribution, were extrapolated ( $\mathrm{a}_{1}$ parameter, Equation [1]). Characteristic $\mathrm{T}_{1}$ and $\mathrm{T}_{2}$ relaxation times were then analyzed in terms of probability density (PDF) and cumulative distribution functions (Statistic Toolbox and Curve Fitting Toolbox, Matlab R2017a version, The MathWorks Inc., Natick, MA) and the best-fitting model was selected according to maximum likelihood estimation. Ranking criterion to select the best-fitting distribution was established according to both log-likelihood (Berger and Wolpert, 1988) and Akaike information criterion (Akaike, 1998).

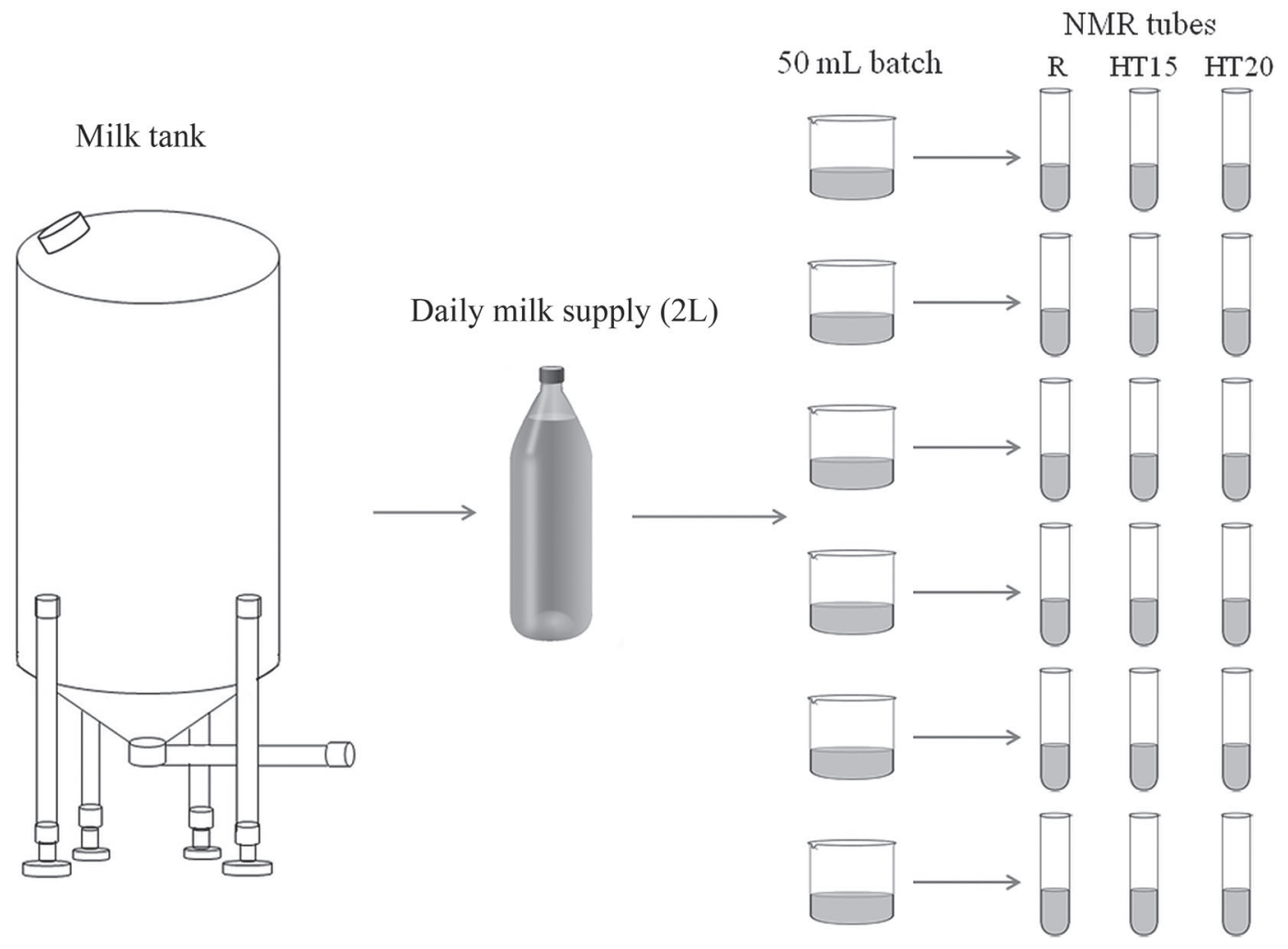

Figure 1. Schematic representation of sampling experimental procedure. NMR = nuclear magnetic resonance; $\mathrm{R}=$ raw; HT15 $=$ heat treatment at $72^{\circ} \mathrm{C}$ for $15 \mathrm{~s}$; HT20 = heat treatment at $72^{\circ} \mathrm{C}$ for $20 \mathrm{~s}$. 
Table 1. Gross mean composition (g/100 g of milk) and SCC of milk during lactation in 2018

\begin{tabular}{lccc}
\hline Item & Mean & Minimum & Maximum \\
\hline pH & 6.66 & 6.61 & 6.70 \\
Fat & 4.93 & 4.46 & 5.31 \\
Protein & 5.19 & 4.95 & 5.33 \\
Casein & 3.94 & 3.73 & 4.08 \\
Lactose & 4.63 & 4.57 & 4.70 \\
SCC $\times 1,000 / \mathrm{mL}$ & 1,127 & 618 & 1,649 \\
\hline
\end{tabular}

\section{Statistical Analysis}

To highlight the effect of thermization on characteristic $\mathrm{T}_{1}$ and $\mathrm{T}_{2}$ constants, $\mathrm{R}$ and HT (15 and $20 \mathrm{~s}$ ) were statistically compared on a daily basis (Prism v 5.03, GraphPad Software, San Diego, CA). The R, HT15, and HT20 were compared by means of ANOVA, and R was individually compared with HT15 and HT20 by a $t$-test $(P \leq 0.05)$.

To better evaluate the heat-driven differences between characteristic $T_{1}$ and $T_{2}$ values of milk (i.e., to highlight the shift of $\mathrm{T}_{1}$ and $\mathrm{T}_{2}$ of HT15 and HT20 with respect to $\mathrm{R}$ samples), delta $(\Delta)$ scores were calculated by subtracting each daily $\mathrm{R}$ value to each daily HT value. Given the intrinsic variability of milk relaxometric properties on different days, deltas were only obtained from samples analyzed the same day, and considering all the possible combinations $\left(\Delta_{\mathrm{HTn}-\mathrm{Rn}} \mathrm{C}_{\mathrm{day}}\right.$, where $\mathrm{n}=$ number of daily measurements and $\mathrm{C}$ indicates all possible combinations according to the notation of combinatorial mathematics). Delta will be identified in the following as $\Delta \mathrm{T}_{1 \text { HT-R }}$ for $\mathrm{T}_{1}$, and $\Delta \mathrm{T}_{2}$ HT-R for $\mathrm{T}_{2}$. Delta values (ms) represent the entity of time constant variation (absolute value) upon heat treatment and indicate the direction of the shift (positive or negative value sign). Statistical comparison of the binary outcome of the $\Delta \mathrm{T}_{1 \text { HT-R }}$ and $\Delta \mathrm{T}_{2}$ HT-R proportions was carried out by chi-squared test, followed by Tukey's honestly significant difference multiple comparison (Matlab Statistic Toolbox, The Mathworks Inc.).

\section{RESULTS AND DISCUSSION}

\section{Milk Composition}

Table 1 shows the composition of raw milk during the season. As expected, fat, protein, and lactose contents are consistent with the average regional values [personal communication of ARA (Breeders Association of Sardinia)].

\section{${ }^{1} H$ TD-NMR}

Representative ${ }^{1} \mathrm{H} \mathrm{T}_{1}$ and $\mathrm{T}_{2}$ distributions of $\mathrm{R}$ and HT, obtained by CONTIN software, are shown in Figure $2 \mathrm{a}$ and $2 \mathrm{~b}$, respectively. The ${ }^{1} \mathrm{H} \mathrm{T}_{1}$ and ${ }^{1} \mathrm{H} \mathrm{T}_{2}$ distributions showed a mono-exponential behavior, with the $\mathrm{T}_{1}$ population relaxing in the range $700-1,700 \mathrm{~ms}$ (peaking at $\sim 900-1,200 \mathrm{~ms}$ ) and $\mathrm{T}_{2}$ in the range $50-150$ $\mathrm{ms}$ (peaking at $\sim 80-110 \mathrm{~ms}$ ). Such features indicate a fast diffusion regimen of water molecules sampling all possible environments in the NMR time scale, but also reflect the complexity of milk at a molecular level, where very different proton domains and mobilities coexist. Similar $\mathrm{T}_{2}$ relaxation times were reported in previous studies on milk model systems, milk protein solutions, and bovine skim milk (Hills et al., 1990; Mariette et al., 1993; Le Dean et al., 2004) and were related to water protons in fast exchange with labile protons of soluble whey proteins and lactose.
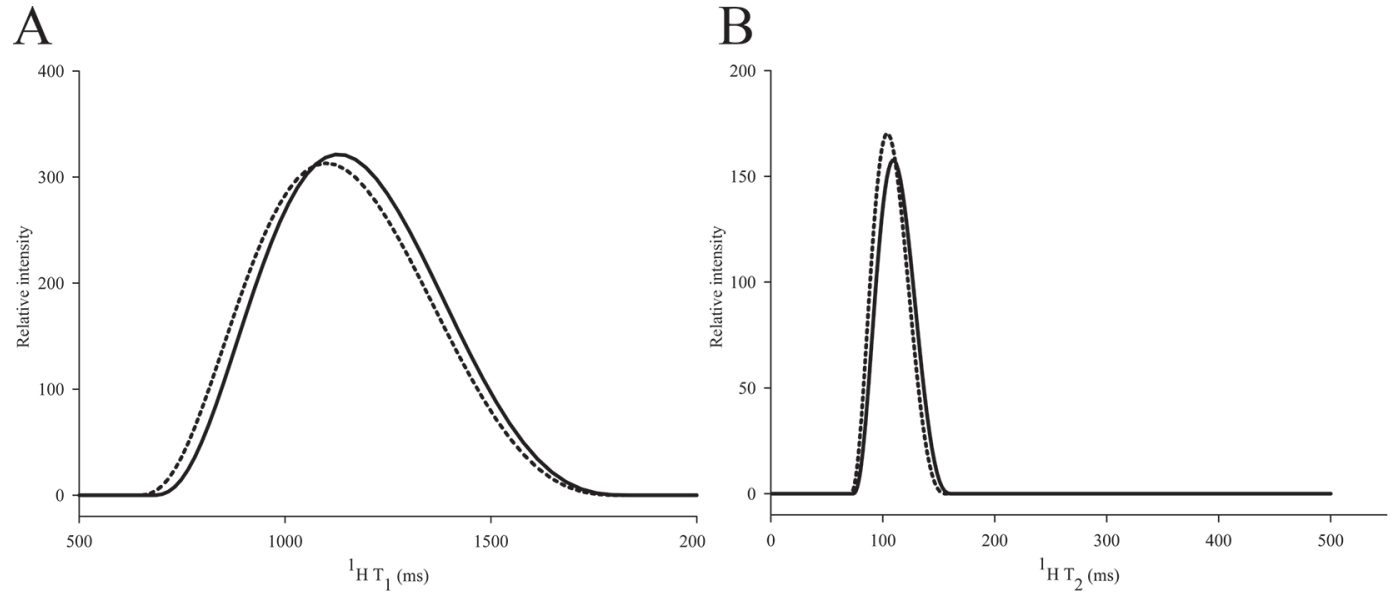

Figure 2. Representative ${ }^{1} \mathrm{H}$ longitudinal relaxation time $\left(\mathrm{T}_{1} ; \mathrm{A}\right)$ and transverse relaxation time $\left(\mathrm{T}_{2} ; \mathrm{B}\right)$ distributions (obtained using CONTIN software, Provencher, 1982; software provided by Bruker, Milan, Italy) of raw (R; solid line) and heat treated (HT; dashed line). 
Characteristic milk $\mathrm{T}_{1}$ and $\mathrm{T}_{2}$ for each day of analysis (calculated from all samples from all batches in the same day) are reported in Tables 2 and 3, respectively. A preliminary statistical analysis (ANOVA, $P \leq 0.05$ ) gave an overall analysis of milk characteristic $\mathrm{T}_{1}$ and $\mathrm{T}_{2}$ changes. Statistics indicated $55.6 \%$ and $75.5 \%$ of significant differences between $\mathrm{R}$ and $\mathrm{HT}$ samples $(P$ $\leq 0.05)$ for $T_{1}$ and $T_{2}$, respectively, regardless of the duration of heat treatment. The comparison between $\mathrm{R}$ and HT15 ( $t$-test, $P \leq 0.05$ ) indicated $58.2 \%$ and $70.3 \%$ of significant differences for $\mathrm{T}_{1}$ and $\mathrm{T}_{2}$, respectively. Comparing $\mathrm{R}$ to HT20, $59.6 \%$ and $80.4 \%$ of significant differences were found for $T_{1}$ and $T_{2}$, respectively.

From February to July a progressive decrease of both $\mathrm{T}_{1}$ and $\mathrm{T}_{2}$ was observed together with a clear monthly grouping for both time constants, indicating some kind of relation between relaxation behavior and the seasonality of milk composition throughout lactation (Supplemental Figure S1; https://doi.org/10.3168/ jds.2019-17617). As shown by PDF corresponding to the beginning (February) and the end (June-July) of lactation, $\mathrm{T}_{1}$ and $\mathrm{T}_{2}$ significantly spread, and with the progress of the season, generated tails in the distributions. More restricted ranges of time constant values were observed during the period from March to May, when the most frequent values of $T_{1}$ and $T_{2}$ were in fact observed.

As a general consideration, it is worth noting that HT samples showed a reduced molecular mobility with respect to $\mathrm{R}$ (distributions shifted toward lower characteristic $\mathrm{T}_{1}$ and $\mathrm{T}_{2}$ ) in all collected data (i.e., $\mathrm{T}_{1}$ and $\mathrm{T}_{2}$ distributions reported in Figure $2 \mathrm{a}$ and $2 \mathrm{~b}$; characteristic $\mathrm{T}_{1}$ and $\mathrm{T}_{2}$ data reported in Tables 2 and 3 ; and PDF of characteristic $T_{1}$ and $T_{2}$ reported in Supplemental Figure S1).

To further characterize this observed shift, it was calculated in the form of delta $(\Delta, \mathrm{ms})$ of characteristic $\mathrm{T}_{1}$ and $\mathrm{T}_{2}$ of HT samples with respect to $\mathrm{R}\left(\Delta \mathrm{T}_{1 \text { HT-R }}\right.$ and $\Delta \mathrm{T}_{2}$ HT-R $)$, on a daily basis. Negative $\Delta \mathrm{T}_{1 \text { HT-R }}$ and $\Delta \mathrm{T}_{2 \text { HT-R }}$ scores (i.e., $\mathrm{R}>\mathrm{HT}$ ) represented the majority of cases (HT15: $\mathrm{T}_{1} \approx 80 \%, \mathrm{~T}_{2} \approx 92 \%$; HT20: $\mathrm{T}_{1} \approx 83$, $\mathrm{T}_{2} \approx 94 \%$ ), with a minor amount of trend-against data (no shift corresponding to $\Delta \mathrm{T}_{1(2) \text { HT-R }} \sim 0$ or shift toward longer times corresponding to $\Delta \mathrm{T}_{1(2) \text { HT-R }}>0$ ). First of all, these data suggest a direct correlation between changes in $T_{1}$ and $T_{2}$ and the duration of heat application (i.e., the amount of thermal energy transferred). Second, the larger percentage of negative $\Delta \mathrm{T}_{2}$ HT-R suggests a higher sensitivity of $\mathrm{T}_{2}$ to heat-induced molecular mobility changes with respect to $T_{1}$.

Statistical significance was only observed in $\Delta \mathrm{T}_{2}$ HT-R, for both HT15 and HT20 (Table 4). The $\Delta \mathrm{T}_{1 \text { HT-R }}$ HT20 was not significant but very close to the significance threshold of $P=0.05$.
Negative values of $\Delta \mathrm{T}_{1 \text { HT-R }}$ (only HT20) and $\Delta \mathrm{T}_{2}$ HT-R were further classified according to their magnitude (Table 5). The $\Delta \mathrm{T}_{1 \text { HT-R }}$ were prevalently larger than 20 ms, whereas the most frequent $\Delta \mathrm{T}_{2}$ HT-R observed fell from 0.5 to $1.5 \mathrm{~ms}$. Increasing the duration of heating (i.e., from 15 to $20 \mathrm{~s}$ ) produced an increase of larger $\Delta \mathrm{T}_{2}$ HT-R and a reduction of smaller ones (Table 5 ).

Several questions may arise when considering further key factors, other than heat treatment, potentially affecting the observed relaxometric changes. We first considered the possibility of water evaporation taking place during heating, but specific trials confirmed that no water evaporation occurred (Supplemental Table S1; https://doi.org/10.3168/jds.2019-17617). In our view, 3 more factors could likely bias the results presented above: sampling variability, $\mathrm{pH}$, and the presence of fat globules. In light of the abovementioned results, a series of additional specific tests were performed to figure out

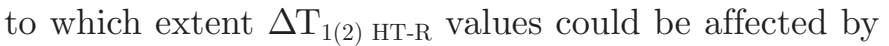
other factors. The role of such factors as potential bias of the observed relaxometric changes will be separately assessed and discussed in the following paragraphs.

\section{Role of Sampling-Induced Variability}

As reported in Tables 2 and 3, we did observe a certain variability in characteristic $T_{1}$ and $T_{2}$ data when milk samples of the same day were compared. Such variability seemed to be amplified when the relaxometric properties of milk samples collected in different days were compared. Likely, sampling from the main tank at the farm site can be a first source of variability to be added to the sampling variability from the bottle to the 50-mL batches in the laboratory and from the batches to the NMR tubes (Figure 1). Therefore, to highlight the effect of heat on relaxometric properties of milk, deltas were calculated only by comparing $\mathrm{R}$ and HT samples analyzed the same day. Reasonably, this variability, originated from the sampling process, could have somewhat contributed to the relaxometric differences between R and HT samples in our study. Therefore, to separately address the effect of heating from that induced by sampling procedures, $\mathrm{T}_{2}$ was measured before and after the heat treatment while keeping the analyzed milk sample in the same NMR tube. With respect to data reported above, the observed negative $\Delta \mathrm{T}_{2}$ HT-R increased in percentage from $92 \%$ to $98 \%$ in HT15 and from $94 \%$ to $100 \%$ in HT20, as expected. Moreover, the percentage of $\Delta \mathrm{T}_{2}$ HT-R classes $1.5-2 \mathrm{~ms}$ and $>2 \mathrm{~ms}$ were also found to increase for both treatments (Table 5; Supplemental Table S2; https://doi.org/10.3168/jds .2019-17617). The observed shifts in relaxometric constants are in this case uniquely ascribed to the effect of the heat treatment, being independent from sampling 
Table 2. Daily longitudinal relaxation time $\left(\mathrm{T}_{1}\right)$ values (ms, mean and $\mathrm{SD}$ ) when at least 3 and up to 6 milk batches (raw, HT15, and HT20 per batch) were analyzed daily (n.m. = not measured) ${ }^{1}$

\begin{tabular}{|c|c|c|c|c|c|c|}
\hline \multirow{2}{*}{$\frac{\text { Day }}{1}$} & \multicolumn{2}{|c|}{ Raw } & \multicolumn{2}{|c|}{ HT15 } & \multicolumn{2}{|c|}{ HT20 } \\
\hline & $1,132.3$ & 11.3 & $1,134.2$ & 3.8 & $1,125.3$ & 5.1 \\
\hline 2 & $1,157.5$ & 8.6 & $1,132.4$ & 10.5 & $1,131.8$ & 8.4 \\
\hline 3 & $1,102.3$ & 4.4 & $1,099.7$ & 7.1 & $1,101.0$ & 1.6 \\
\hline 4 & $1,133.8$ & 6.6 & $1,141.5$ & 12.9 & $1,143.3$ & 12.9 \\
\hline 5 & $1,113.4$ & 6.8 & $1,119.2$ & 6.0 & $1,111.5$ & 5.6 \\
\hline 6 & $1,127.2$ & 27.9 & $1,093.8$ & 5.8 & $1,080.3$ & 6.8 \\
\hline 7 & $1,127.3$ & 5.7 & n.m. & n.m. & 1,122.2 & 3.6 \\
\hline 8 & $1,117.7$ & 6.6 & $1,104.4$ & 8.4 & $1,105.9$ & 3.0 \\
\hline 9 & $1,111.2$ & 14.4 & $1,107.8$ & 5.2 & $1,105.6$ & 6.3 \\
\hline 10 & $1,137.7$ & 11.2 & $1,138.5$ & 7.7 & $1,135.2$ & 4.5 \\
\hline 11 & $1,111.8$ & 5.8 & $1,113.1$ & 10.8 & $1,112.4$ & 4.5 \\
\hline 12 & $1,126.8$ & 5.2 & $1,116.4$ & 6.8 & $1,117.4$ & 6.3 \\
\hline 13 & $1,145.4$ & 16.3 & $1,127.4$ & 10.7 & $1,128.9$ & 15.9 \\
\hline 14 & $1,119.1$ & 7.2 & 1,111.1 & 5.8 & 1,113.7 & 2.7 \\
\hline 15 & $1,137.6$ & 3.1 & $1,127.2$ & 7.9 & $1,137.3$ & 11.3 \\
\hline 16 & $1,147.9$ & 6.2 & $1,149.1$ & 4.5 & $1,144.5$ & 3.8 \\
\hline 17 & $1,125.0$ & 5.0 & $1,110.9$ & 7.6 & $1,113.5$ & 4.0 \\
\hline 18 & $1,173.4$ & 4.9 & $1,154.1$ & 4.7 & $1,157.3$ & 7.8 \\
\hline 19 & $1,126.8$ & 4.6 & $1,120.9$ & 2.8 & $1,116.3$ & 5.2 \\
\hline 20 & $1,081.2$ & 7.5 & $1,072.3$ & 7.2 & $1,076.6$ & 7.4 \\
\hline 21 & $1,136.0$ & 16.3 & $1,133.0$ & 14.7 & 1,129.1 & 11.8 \\
\hline 22 & $1,155.6$ & 15.5 & $1,150.4$ & 14.6 & $1,154.7$ & 14.1 \\
\hline 23 & $1,169.6$ & 8.0 & $1,165.1$ & 4.4 & $1,161.5$ & 7.7 \\
\hline 24 & $1,159.2$ & 5.2 & $1,156.2$ & 3.9 & $1,159.0$ & 9.8 \\
\hline 25 & $1,143.1$ & 6.4 & $1,136.0$ & 3.4 & 1,129.6 & 10.2 \\
\hline 26 & $1,177.6$ & 12.0 & $1,176.2$ & 4.8 & $1,180.9$ & 10.1 \\
\hline 27 & $1,152.5$ & 2.7 & $1,132.1$ & 2.5 & 1,129.6 & 7.2 \\
\hline 28 & $1,099.9$ & 3.3 & $1,086.4$ & 4.0 & $1,084.5$ & 4.6 \\
\hline 29 & $1,158.7$ & 3.4 & $1,153.9$ & 5.2 & $1,157.9$ & 0.9 \\
\hline 30 & $1,146.4$ & 7.7 & $1,114.9$ & 4.1 & $1,113.9$ & 9.5 \\
\hline 31 & $1,147.0$ & 4.9 & $1,146.6$ & 4.8 & $1,141.2$ & 8.9 \\
\hline 32 & $1,106.2$ & 6.6 & $1,102.8$ & 5.5 & $1,094.2$ & 10.0 \\
\hline 33 & $1,102.6$ & 8.0 & $1,082.9$ & 6.2 & $1,086.7$ & 5.4 \\
\hline 34 & $1,162.6$ & 1.7 & $1,157.9$ & 9.0 & $1,159.8$ & 4.2 \\
\hline 35 & $1,088.1$ & 4.6 & $1,075.0$ & 11.4 & 1,090.1 & 47.6 \\
\hline 36 & $1,152.2$ & 7.9 & $1,144.8$ & 3.8 & $1,147.3$ & 6.4 \\
\hline 37 & $1,114.2$ & 7.9 & $1,091.0$ & 5.1 & $1,088.0$ & 10.5 \\
\hline 38 & $1,198.4$ & 2.9 & $1,152.0$ & 4.1 & $1,150.8$ & 4.2 \\
\hline 39 & $1,152.2$ & 3.6 & $1,145.7$ & 6.2 & $1,145.9$ & 8.9 \\
\hline 40 & $1,068.7$ & 9.5 & $1,070.2$ & 12.9 & $1,067.0$ & 9.6 \\
\hline 41 & $1,102.8$ & 9.3 & $1,097.9$ & 7.3 & $1,091.4$ & 8.1 \\
\hline 42 & $1,087.0$ & 21.0 & $1,076.5$ & 12.4 & $1,070.9$ & 4.0 \\
\hline 43 & $1,173.0$ & 4.4 & $1,148.2$ & 4.8 & $1,151.7$ & 0.3 \\
\hline 44 & $1,173.8$ & 9.8 & $1,158.1$ & 8.6 & $1,157.8$ & 9.1 \\
\hline 45 & $1,169.6$ & 3.6 & $1,162.6$ & 3.6 & $1,163.5$ & 7.8 \\
\hline 46 & $1,136.1$ & 7.9 & $1,133.4$ & 13.4 & $1,132.6$ & 12.1 \\
\hline 47 & $1,133.5$ & 5.1 & $1,107.4$ & 4.3 & $1,101.7$ & 4.5 \\
\hline 48 & $1,095.9$ & 6.8 & $1,095.1$ & 6.8 & $1,094.9$ & 9.2 \\
\hline 49 & $1,132.4$ & 10.1 & $1,108.7$ & 9.6 & $1,110.8$ & 5.1 \\
\hline 50 & $1,155.5$ & 6.3 & $1,153.8$ & 6.5 & $1,152.0$ & 8.6 \\
\hline 51 & $1,141.3$ & 5.5 & $1,115.2$ & 11.0 & $1,108.4$ & 8.1 \\
\hline 52 & $1,054.7$ & 12.8 & $1,046.4$ & 6.0 & $1,042.6$ & 5.1 \\
\hline 53 & $1,074.8$ & 9.6 & $1,079.6$ & 6.9 & $1,082.7$ & 28.0 \\
\hline 54 & $1,101.5$ & 11.2 & $1,099.5$ & 28.7 & $1,084.3$ & 19.7 \\
\hline 55 & $1,084.0$ & 6.7 & $1,078.6$ & 7.3 & $1,073.3$ & 13.6 \\
\hline 56 & $1,114.3$ & 5.7 & $1,104.8$ & 7.7 & $1,107.0$ & 9.3 \\
\hline 57 & 1,133.8 & 6.2 & 1,129.6 & 7.1 & $1,126.3$ & 9.2 \\
\hline 58 & $1,082.9$ & 7.0 & $1,071.3$ & 7.2 & $1,059.0$ & 9.1 \\
\hline 59 & $1,098.7$ & 8.9 & $1,075.7$ & 11.4 & $1,078.4$ & 12.2 \\
\hline 60 & $1,137.2$ & 5.7 & $1,120.5$ & 3.9 & $1,119.2$ & 4.7 \\
\hline 61 & $1,066.4$ & 5.2 & $1,049.9$ & 7.8 & $1,045.0$ & 9.7 \\
\hline 62 & $1,059.2$ & 14.3 & $1,051.7$ & 1.8 & $1,052.2$ & 6.3 \\
\hline 63 & $1,070.4$ & 8.6 & $1,050.8$ & 11.6 & $1,056.7$ & 12.5 \\
\hline 64 & $1,099.8$ & 8.5 & $1,085.9$ & 21.1 & $1,082.2$ & 4.2 \\
\hline 65 & $1,083.4$ & 2.5 & $1,065.1$ & 1.2 & $1,059.0$ & 6.7 \\
\hline
\end{tabular}


Table 2 (Continued). Daily longitudinal relaxation time $\left(\mathrm{T}_{1}\right)$ values (ms, mean and $\mathrm{SD}$ ) when at least 3 and up to 6 milk batches (raw, HT15, and HT20 per batch) were analyzed daily (n.m. = not measured) ${ }^{1}$

\begin{tabular}{|c|c|c|c|c|c|c|}
\hline \multirow{2}{*}{$\frac{\text { Day }}{66}$} & \multicolumn{2}{|c|}{ Raw } & \multicolumn{2}{|c|}{ HT15 } & \multicolumn{2}{|c|}{ HT20 } \\
\hline & $1,086.3$ & 5.4 & $1,069.9$ & 3.9 & $1,074.7$ & 7.2 \\
\hline 67 & $1,079.6$ & 15.1 & $1,052.2$ & 7.8 & $1,028.6$ & 67.9 \\
\hline 68 & $1,105.0$ & 7.6 & $1,093.5$ & 10.5 & $1,091.4$ & 6.1 \\
\hline 69 & $1,052.7$ & 6.3 & $1,039.4$ & 4.6 & $1,034.6$ & 9.4 \\
\hline 70 & $1,114.3$ & 9.6 & $1,096.5$ & 5.6 & $1,089.3$ & 8.1 \\
\hline 71 & $1,075.0$ & 13.0 & $1,061.7$ & 3.1 & $1,060.5$ & 7.0 \\
\hline 72 & $1,112.8$ & 5.3 & $1,084.6$ & 3.6 & $1,085.3$ & 8.1 \\
\hline 73 & $1,055.8$ & 10.6 & $1,046.1$ & 10.4 & $1,042.9$ & 11.5 \\
\hline 74 & $1,079.2$ & 3.3 & $1,064.3$ & 4.1 & $1,060.8$ & 7.8 \\
\hline 75 & $1,145.5$ & 11.8 & $1,121.9$ & 5.6 & $1,118.5$ & 9.0 \\
\hline 76 & $1,098.1$ & 7.7 & $1,091.3$ & 7.9 & $1,085.6$ & 6.5 \\
\hline 77 & $1,099.8$ & 4.9 & $1,083.4$ & 8.8 & $1,086.3$ & 3.9 \\
\hline 78 & $1,134.4$ & 8.4 & $1,109.6$ & 2.9 & $1,106.4$ & 9.7 \\
\hline 79 & $1,113.3$ & 2.2 & $1,091.8$ & 9.6 & $1,091.7$ & 3.3 \\
\hline 80 & 1,133.6 & 14.9 & $1,098.1$ & 7.1 & 1,091.4 & 3.5 \\
\hline 81 & $1,076.0$ & 7.3 & $1,056.8$ & 11.5 & $1,066.4$ & 8.6 \\
\hline 82 & $1,115.3$ & 10.6 & $1,097.6$ & 4.7 & $1,097.5$ & 6.8 \\
\hline 83 & $1,106.1$ & 6.4 & $1,091.8$ & 4.3 & $1,090.4$ & 5.5 \\
\hline 84 & $1,070.7$ & 9.0 & $1,056.5$ & 4.6 & $1,055.5$ & 8.8 \\
\hline 85 & $1,109.3$ & 2.7 & $1,080.3$ & 3.5 & $1,070.9$ & 7.0 \\
\hline 86 & $1,016.9$ & 9.9 & $1,001.9$ & 6.7 & 993.1 & 6.2 \\
\hline 87 & $1,035.8$ & 8.7 & $1,015.9$ & 9.6 & $1,014.2$ & 2.9 \\
\hline 88 & $1,039.3$ & 15.4 & 992.3 & 5.7 & 989.4 & 7.1 \\
\hline 89 & 930.9 & 13.5 & 921.4 & 13.8 & 920.2 & 12.8 \\
\hline 90 & $1,022.1$ & 3.4 & $1,006.3$ & 4.3 & $1,010.9$ & 4.3 \\
\hline 91 & $1,002.3$ & 5.1 & 990.7 & 3.8 & 990.1 & 9.3 \\
\hline 92 & $1,066.9$ & 12.9 & $1,042.8$ & 4.4 & $1,036.0$ & 7.7 \\
\hline 93 & $1,082.3$ & 10.9 & $1,022.8$ & 3.6 & $1,023.4$ & 3.6 \\
\hline 94 & 968.3 & 5.6 & 957.6 & 4.4 & 954.5 & 4.9 \\
\hline 95 & $1,026.3$ & 4.2 & $1,003.2$ & 2.5 & $1,000.9$ & 0.9 \\
\hline 96 & 958.7 & 4.1 & 957.4 & 2.0 & 956.4 & 0.9 \\
\hline 97 & 998.1 & 2.2 & 979.1 & 4.7 & 974.2 & 0.8 \\
\hline 98 & $1,043.6$ & 8.1 & $1,003.4$ & 9.0 & $1,006.8$ & 13.3 \\
\hline 99 & 976.1 & 3.1 & 962.8 & 7.5 & 959.5 & 4.7 \\
\hline 100 & 984.2 & 6.1 & 968.4 & 6.6 & 963.3 & 3.9 \\
\hline 101 & 973.8 & 4.7 & 959.4 & 5.8 & 959.8 & 1.6 \\
\hline 102 & 986.2 & 13.2 & 964.5 & 3.3 & 963.4 & 4.1 \\
\hline 103 & 980.9 & 2.0 & 968.5 & 3.5 & 971.8 & 3.8 \\
\hline
\end{tabular}

${ }^{1} \mathrm{HT} 15=$ heat treatment at $72^{\circ} \mathrm{C}$ for $15 \mathrm{~s}$; HT20 = heat treatment at $72^{\circ} \mathrm{C}$ for $20 \mathrm{~s}$.

procedures. Based on these results, we can conclude that sampling-induced variability can partially mask the effect of heat treatment on TD-NMR relaxation parameters. Nonetheless, a daily analysis of real samples is still able to discriminate raw from HT milk.

\section{Role of $\mathrm{pH}$}

Milk $\mathrm{pH}$ is paramount for colloidal equilibrium and well-known alterations in milk component stability occur as a consequence of a $\mathrm{pH}$ drop (e.g., solubilization of micellar calcium phosphate, dissociation of casein micelles; de la Fuente, 1998; Walstra et al., 2005). Several factors, including temperature, can influence milk $\mathrm{pH}$. Heating affects salt distribution among the milk phases, with the formation of additional colloidal phosphate from the dissociation of calcium and phosphate, accompanied by $\mathrm{H}^{+}$ion release and $\mathrm{pH}$ decrease
(Walstra et al., 2005; Fox, 2015). The equilibrium is readily restored on cooling after heating to a moderate temperature $\left(<95^{\circ} \mathrm{C}\right.$; van Dijk and Hersevoort, 1992) and the nonreversibility (or slow reversibility) of the reaction is proportional to the severity of treatment (Pouliot et al., 1989). The kinetics of $\mathrm{pH}$ equilibrium restoring process should be taken into account in the case of severe heating conditions (e.g., $24 \mathrm{~h}$ at $4^{\circ} \mathrm{C}$ after a heating treatment at $90^{\circ} \mathrm{C}$ for $10 \mathrm{~min}$ in bovine milk, according to Chandrapala et al., 2010). However, according to Walstra et al. (1999), irreversible reactions scarcely occur in milk submitted to a treatment milder than HTST pasteurization (e.g., $72^{\circ} \mathrm{C}, 15 \mathrm{~s}$ ).

It has been demonstrated that a variation of $\mathrm{pH}$ can result in changes in NMR transverse relaxation $\left(\mathrm{T}_{2}\right)$ in reconstituted skim milk and caseinate-whey mixtures (Mariette et al., 1993). In particular, the transverse relaxation rate $R_{2}$ (where $R_{2}=1 / T_{2}$ ) decreases with 
Table 3. Daily transverse relaxation time $\left(\mathrm{T}_{2}\right)$ values (ms, mean, and $\mathrm{SD}$ ); at least 3 and up to 6 milk batches (raw, HT15, and HT20 per batch) were analyzed daily ${ }^{1}$

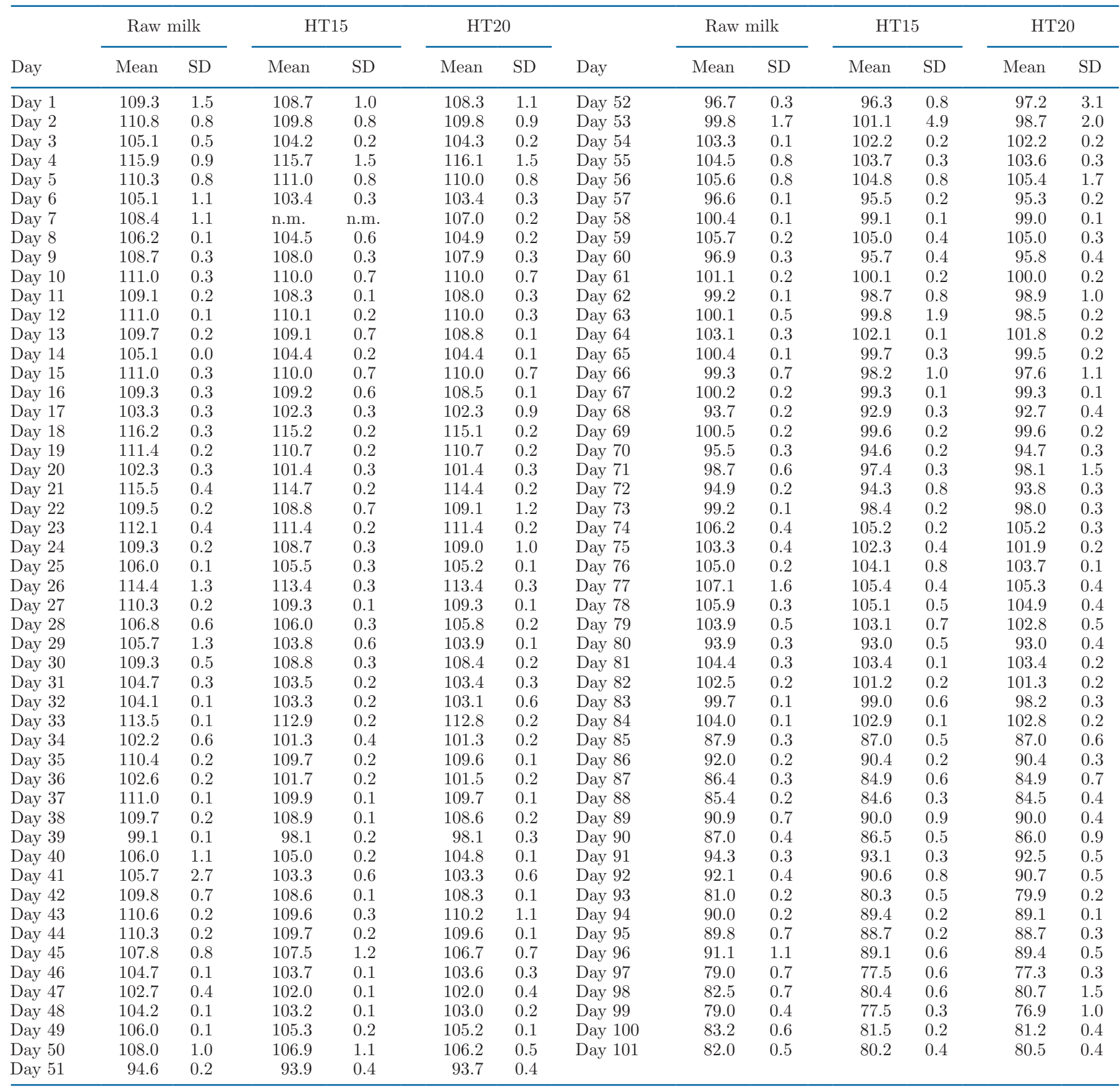

${ }^{1} \mathrm{HT} 15=$ heat treatment at $72^{\circ} \mathrm{C}$ for $15 \mathrm{~s} ; \mathrm{HT} 20=$ heat treatment at $72^{\circ} \mathrm{C}$ for $20 \mathrm{~s} ; \mathrm{n} . \mathrm{m} .=$ not measured.

decreasing $\mathrm{pH}$ values, reaching a minimum at $\mathrm{pH}=$ 5.3. Such effect has been ascribed to both a change in the hydration status of micelles, due to the alteration in composition and structure of casein particles upon acidification, and to the dissolution of micellar calcium and phosphorus (Mariette et al., 1993).
According to the abovementioned dependence of milk $\mathrm{T}_{2}$ on $\mathrm{pH}$, an increase in $\mathrm{T}_{2}$ should be expected upon heat treatment, due to the inverse relation between $\mathrm{pH}$ and $\mathrm{T}_{2}$. However, changes of $\mathrm{pH}$ following heat treatment, in agreement with previous findings, were negligible or very subtle (Supplemental Table S3; 
Table 4. Multiple comparisons (chi-square with associated Tukey's honestly significant difference test) among the binary outcomes of delta longitudinal relaxation time $\left(T_{1}\right)$ and transverse relaxation time $\left(T_{2}\right)$ values ${ }^{1}$

\begin{tabular}{lclll}
\hline Item & Differences & $\mathrm{SE}$ & $P$-value & Decision \\
\hline$\Delta \mathrm{T}_{1 \text { HT15-R }}$ & 0.2396 & 4.603 & $P=0.90742$ & $\mathrm{NS}$ \\
$\Delta \mathrm{T}_{1 \text { HT20-R }}$ & 1.9932 & 3.128 & $P=0.05574$ & $\mathrm{NS}$ \\
$\Delta \mathrm{T}_{2 \text { HT15-R }}$ & 10.597 & 2.18 & $P=0.00972$ & $* *$ \\
$\Delta \mathrm{T}_{2 \text { HT20-R }}$ & 12.3507 & 1.115 & $P=2.1034 \times 10^{-5}$ & $* * *$ \\
\hline
\end{tabular}

${ }^{1}$ Listed parameters include cumulative difference values after arcsin transformation and SE, with a given significance level of $P<0.05$ to assess the significant threshold of the multiple comparisons.

** $P<0.01 ; * * * P<0.001$.

https://doi.org/10.3168/jds.2019-17617) and often fall within the experimental error of the $\mathrm{pH}$ meter $(0.01 \mathrm{pH}$ points).

We decided to accurately estimate the dependence of NMR relaxation on $\mathrm{pH}$ in whole ewe milk by means of an NMR relaxation-based titration (Supplemental File S1; https://doi.org/10.3168/jds.2019-17617). Results are in line with those previously reported in literature for skim milk and other dairy protein solutions (Mariette et al., 1993). According to these results, considering a heat-driven decrease of $\mathrm{pH}$ (i.e., $\mathrm{pH}_{\mathrm{HT}}<\mathrm{pH}_{\mathrm{R}}$ ), a corresponding $\mathrm{T}_{2}$ increase would be opposite to its decrease reported in the present data. The lack of an observation of $\mathrm{T}_{2}$ increase upon heating allowed the exclusion of any role of $\mathrm{pH}$ on the relaxometric constants shift. In any case, very subtle variations of milk $\mathrm{pH}$ could contribute to the observed sample variability of relaxation time constants by partially masking the heat-induced $\mathrm{T}_{2}$ shift.

\section{Role of Fat Globules}

The presented relaxometric responses of whole milk to a heat treatment are similar to those previously obtained in fat free milk-like models and reconstituted skim milk of different origin (Lambelet et al., 1992; Mariette et al., 1993). To accomplish a more accurate description of the behavior of whole milk, the role played by fat in the relaxometric profiles upon heat treatment was specifically evaluated by dedicated experiments.

Table 5. Classification of delta $\left(\Delta \mathrm{T}_{1 \text { HT-R }}\right.$ and $\Delta \mathrm{T}_{2}$ HT-R $)$, expressed as percentage of the subset of negative delta ${ }^{1}$

\begin{tabular}{lrrlrr}
\hline$\Delta \mathrm{T}_{1 \text { HT-R }}$ & HT15 & HT20 & $\Delta \mathrm{T}_{2 \text { HT-R }}$ & HT15 & HT20 \\
\hline $1-5 \mathrm{~ms}$ & 10.7 & 10.1 & $0.1-0.5 \mathrm{~ms}$ & 12.7 & 8.1 \\
$5-10 \mathrm{~ms}$ & 17.4 & 17.9 & $0.5-1 \mathrm{~ms}$ & 41.9 & 36.2 \\
$10-15 \mathrm{~ms}$ & 18.4 & 15.5 & $1-1.5 \mathrm{~ms}$ & 30.2 & 35.7 \\
$15-20 \mathrm{~ms}$ & 16.0 & 15.7 & $1.5-2 \mathrm{~ms}$ & 9.1 & 11.7 \\
$>20 \mathrm{~ms}$ & 37.4 & 40.7 & $>2 \mathrm{~ms}$ & 6.2 & 8.4 \\
\hline
\end{tabular}

${ }^{1} \mathrm{~T}_{1}=$ longitudinal relaxation time; $\mathrm{T}_{2}=$ transverse relaxation time; $\mathrm{HT}-\mathrm{R}=$ heat treated raw; HT15 = heat treatment at $72^{\circ} \mathrm{C}$ for $15 \mathrm{~s}$; $\mathrm{HT} 20=$ heat treatment at $72^{\circ} \mathrm{C}$ for $20 \mathrm{~s}$.
Role of Fat Globule Inhomogeneity. Official methods for characterizing milk physico-chemical properties require the homogenization of milk fat fraction (925.21, Association of Official Analytical Chemists, 1990) before further measurements. In fact, a certain degree of inhomogeneity can be observed in the fat phase (Marth, 1978), especially when milk is kept at refrigerated temperatures after milking. In this study, milk was intentionally not homogenized before NMR analysis (as suggested by official methods), to avoid any additional heat transfer beyond pasteurization. However, specific trials were conducted following the official method to verify if the observed variability could be ascribable to the inhomogeneity of fat. The relaxometric differences between raw and heat treated were still present in the homogenized samples (Supplemental Figure S2; https:/ /doi.org/10.3168/jds.2019-17617), suggesting that they were not ascribable to inhomogeneities in the milk fat globule phase.

Role of Milk Skimming. Skim milk always exhibited higher $\mathrm{T}_{2}$ values than whole milk (Supplemental Figure S3; https://doi.org/10.3168/jds.2019-17617). Such result can be preliminarily explained with the dilution effect due to skimming. Furthermore, NMR relaxation is likely influenced by the effect of fat globules that either slow down the overall molecular mobility in milk, making it a more viscous solution (Bakshi and Smith, 1984) than skim milk, and promote chemical exchange between water protons and their faster relaxing protons. Additionally, it could be reasonably argued that proton relaxation is enhanced by water diffusion through magnetic gradients generated by the presence of fat globules (Hills et al., 1990).

To more deeply understand how fat actually modulates the NMR relaxation of whole milk upon heating, $\Delta \mathrm{T}_{2}$ HT-R of whole and skim milk were derived. In fact, if the presence of fat were a significant driving factor of the $\Delta T_{2 \text { HT-R }}$ increase of whole milk, then the expected $\Delta \mathrm{T}_{2}$ HT-R of skim milk would be smaller. According to experimental data, however, $\Delta \mathrm{T}_{2}$ HT-R of skim milk were similar to those of whole milk (0.5-2 ms; Supplemental Table S4; https://doi.org/10.3168/jds.2019-17617), suggesting that relaxometric changes are most largely 
influenced by molecular changes in the protein fraction or in other soluble molecular components rather than by fat.

We further investigated this behavior by comparing $\mathrm{T}_{2}$ of milk which was heat treated and then skimmed (treated skim) to milk that was first skimmed and then heat treated (skim treated; Supplemental Table S5; https://doi.org/10.3168/jds.2019-17617). Treated skim samples had significantly higher $\mathrm{T}_{2}$ than skim treated counterparts ( $t$-test, $P<0.001$ ). These data confirm previous evidence of strong interactions between fat globules and other components, due to milk heating (Corredig and Dalgleish, 1996), and corroborates the hypothesis that the heat treatment itself changes the relaxation properties of milk by involving not only polar (proteins, lactose, and so on) but also fat components. It is reasonable to assume that molecular interactions are established between $\beta-\mathrm{LG}$ and denaturated milk fat globule membrane (MFGM) proteins during heating. Moreover, fat could cause a partial "retention" of whey proteins and other species during the skimming process, resulting in a reduced availability of relaxation sinks (i.e., relaxation-promoting agents) in the corresponding treated skim sample (Corredig and Dalgleish, 1996; Ye et al., 2004).

\section{Can TD-NMR Relaxometric Profiles Be Related to Heat-Induced Molecular Changes in Milk?}

Previous studies investigated the modifications of milk components when a heat treatment is applied. Whey proteins exhibit reversible modifications at temperatures $<60^{\circ} \mathrm{C}$ (Fox et al., 2015), with partial unfolding that can evolve to irreversible aggregation (via disulfide bonds formation between denatured $\beta$-LG) at more severe heating conditions (e.g., temperature $>70^{\circ} \mathrm{C}$; deWit and Klarenbeek, 1984; Wijayanti et al., 2014; Fox et al., 2015). $\beta$-Lactoglobulins can also interact with $\kappa$ - and $\alpha_{S_{2}}$-caseins, resulting in the "coating" of casein micelles by whey proteins. The aforementioned phenomena were described in bovine milk (Vasbinder and De Kruif, 2003), but since ruminant whey protein polymorphism consists of few genetic variants, without significant amino acid substitutions, it is reasonable to infer that a similar protein unfolding mechanism may also characterize whey proteins denaturation in sheep milk (Juarez and Ramos, 2003; Hernández-Ledesma et al., 2008). This is especially convincing if the lower thermostability of ovine $\beta-\mathrm{LG}$ is considered (El-Zahar et al., 2004; Balthazar et al., 2017). In the same way, proteins of MFGM are affected by heat (temperature $>70^{\circ} \mathrm{C}$ ) and can interact with whey proteins, via disulfide interac- tions, leading to the formation of aggregates (Corredig and Dalgleish, 1996; Ye et al., 2004; Huppertz and Kelly, 2006).

Based on our data, a change in ewe milk molecular dynamics (decrease in $\mathrm{T}_{1}$ and $\mathrm{T}_{2}$ ), following HTST treatment, is consistently observable. Previous NMRrelaxometry reports considered more severe heating conditions in milk model systems (from $20^{\circ} \mathrm{C}$ to $90^{\circ} \mathrm{C}$ for an extended time, $30 \mathrm{~min}$; Lambelet et al., 1992) and associated an increase in the transverse relaxation rate $R_{2}\left(R_{2}=1 / T_{2}\right)$ to a rigidity gain in whey protein backbone protons, due to protein denaturation. The time-temperature conditions of the heat treatment applied in this experimentation were likely not sufficient to allow the same degree of protein denaturation of that measured in previous trials. However, the consistent shift toward shorter times upon industrial-like heat treatment shown here indicates a coherent relaxometric change ascribable to dynamic perturbations in protein molecular arrangement. With proteins in a pre-denaturational stage, the observed faster relaxation showed by HT samples could be related to a variation in their hydration status that promotes proton relaxation (Mariette et al., 1993; Hinrichs et al., 2004). Other possible relaxation-promoting factors are the establishment of a higher degree of disorder (random coil structure, molten globule state; Bhattacharjee et al., 2005) and aggregation caused by disulfide-links and noncovalent interactions involving whey proteins (Hoffmann and van Mil, 1997; Halle, 2004). A contribution to the faster relaxation could be attributed to an interaction of MFGM with whey proteins, as previously discussed.

\section{CONCLUSIONS}

In this work we provided an extensive collection of relaxometric data on whole ewe milk related to different periods of lactation. We considered important the choice to investigate a "real" milk system to evaluate the potentiality of TD-NMR applied to complex systems that were scarcely considered in previous literature. The observed data demonstrate TD-NMR is able to detect heat-induced changes in whole ewe milk molecular dynamics, which are uniquely ascribable to the application of a heat treatment. In fact, the analyzed contribution of other factors beyond heat, such as $\mathrm{pH}$ and fat, to the observed modifications of NMR relaxation parameters was not significant. The presented results suggest the possibility of further exploiting TD-NMR as a technique for dairy industry applications and paving the way for novel applications of TD-NMR in quality control and assessment. 


\section{ACKNOWLEDGMENTS}

This work was supported by Regione Autonoma della Sardegna, Italy (Legge Regionale n. 15, 17.11.2010). The authors have no conflicts of interest to declare.

\section{REFERENCES}

Akaike, H. 1998. Information theory and an extension of the maximum likelihood principle. Pages 199-213 in Selected Papers of Hirotugu Akaike. E. Parzen, K. Tanabe, and G. Kitagawa, ed. Springer, New York, NY.

Anedda, R. 2015. Magnetic resonance analysis of dairy processing: Suitable tools for the dairy industry. Pages 51-64 in Magnetic Resonance in Food Science: Defining Food by Magnetic Resonance, F. Capozzi, L. Laghi, and P. S. Belton, ed. Royal Society of Chemistry, London, UK.

Association of Official Analytical Chemists. 1990. Official Methods of Analysis, 15th ed. Association of Official Analytical Chemists, Arlington, VA.

Bakshi, A. S., and D. E. Smith. 1984. Effect of fat content and temperature on viscosity in relation to pumping requirements of fluid milk products. J. Dairy Sci. 67:1157-1160. https://doi.org/10 .3168/jds.S0022-0302(84)81417-4.

Balthazar, C. F., T. C. Pimentel, L. L. Ferrão, C. N. Almada, A. Santillo, M. Albenzio, N. Mollakhalili, A. M. Mortazavian, J. S. Nascimento, M. C. Silva, M. Q. Freitas, A. S. Sant'Ana, D. Granato, and A. G. Cruz. 2017. Sheep milk: Physicochemical characteristics and relevance for functional food development. Compr. Rev. Food Sci. Food Saf. 16:247-262. https://doi.org/10.1111/1541-4337 .12250 .

Berger, J. O., and R. L. Wolpert. 1988. The likelihood principle and generalization. Pages 19-64 in The Likelihood Principle. Lecture Notes-Monograph Series, Vol. 6. Shanti S. Gupta, ed. Institute of Mathematical Statistics, Hayward, CA.

Bhattacharjee, C., S. Saha, A. Biswas, M. Kundu, L. Ghosh, and K. P. Das. 2005. Structural changes of $\beta$-lactoglobulin during thermal unfolding and refolding-an FT-IR and circular dichroism study. Protein J. 24:27-35. https://doi.org/10.1007/s10930-004-0603-z.

Buchin, S., V. Delague, G. Duboz, J. L. Berdague, E. Beuvier, S. Pochet, and R. Grappin. 1998. Influence of pasteurization and fat composition of milk on the volatile compounds and flavor characteristics of a semi-hard cheese. J. Dairy Sci. 81:3097-3108. https:/ /doi.org/10.3168/jds.S0022-0302(98)75874-6.

Caboni, P., D. Maxia, P. Scano, M. Addis, A. Dedola, M. Pes, A. Murgia, M. Casula, A. Profumo, and A. Pirisi. 2019. A gas chromatography-mass spectrometry untargeted metabolomics approach to discriminate Fiore Sardo cheese produced from raw or thermized ovine milk. J. Dairy Sci. 102:5005-5018. https://doi .org/10.3168/jds.2018-15885.

Calvo, M. M., and E. Balcones. 2000. Some factors influencing the syneresis of bovine, ovine, and caprine milks. J. Dairy Sci. 83:17331739. https://doi.org/10.3168/jds.S0022-0302(00)75043-0.

Chandrapala, J., I. McKinnon, M. A. Augustin, and P. Udabage. 2010. The influence of milk composition on $\mathrm{pH}$ and calcium activity measured in situ during heat treatment of reconstituted skim milk. J. Dairy Res. 77:257-264. https://doi.org/10.1017/ S0022029910000026.

Corredig, M., and D. G. Dalgleish. 1996. Effect of different heat treatments on the strong binding interactions between whey proteins and milk fat globules in whole milk. J. Dairy Res. 63:441-449. https://doi.org/10.1017/S0022029900031940.

Curti, E., A. Pardu, S. Del Vigo, R. Sanna, and R. Anedda. 2019. Non invasive monitoring of curd syneresis upon renneting of raw and heat-treated cow's and goat's milk. Int. Dairy J. 90:95-97. https:/ /doi.org/10.1016/j.idairyj.2018.11.003.

de la Fuente, M. A. 1998. Changes in the mineral balance of milk submitted to technological treatments. Trends Food Sci. Technol. 9:281-288. https://doi.org/10.1016/S0924-2244(98)00052-1.
deWit, J. N., and G. Klarenbeek. 1984. Effects of various heat treatments on structure and solubility of whey proteins. J. Dairy Sci. 67:2701-2710. https://doi.org/10.3168/jds.S0022-0302(84)81628 -8 .

El-Zahar, K., M. Sitohy, M. Dalgalarrondo, Y. Choiset, F. Métro, T. Haertlé, and J. Chobert. 2004. Purification and physicochemical characterization of ovine $\beta$-lactoglobulin and $\alpha$-lactalbumin. Food/ Nahrung 48:177-183. https://doi.org/10.1002/food.200300447.

European Commission. 2006. Commission Regulation No 1664/2006 amending Regulation (EC) No 2074/2005 as regards implementing measures for certain products of animal origin intended for human consumption and repealing certain implementing measures, 2006 O.J. L 320.

Fox, P. F., T. Uniacke-Lowe, P. L. H. McSweeney, and J. A. O'Mahony. 2015. Heat-induced changes in milk. Pages $345-375$ in Dairy Chemistry and Biochemistry. 2nd ed. Springer, Cham, Switzerland. https://doi.org/10.1007/978-3-319-14892-2_9.

Halle, B. 2004. Protein hydration dynamics in solution: A critical survey. Philos. Trans. R. Soc. Lond. B Biol. Sci. 359:1207-1223. https: //doi.org/10.1098/rstb.2004.1499.

Hansen, C. L., Å. Rinnan, S. B. Engelsen, T. Janhøj, E. Micklander, U. Andersen, and F. van den Berg. 2010. Effect of gel firmness at cutting time, $\mathrm{pH}$, and temperature on rennet coagulation and syneresis: An in situ ${ }^{1} \mathrm{H}$ NMR relaxation study. J. Agric. Food Chem. 58:513-519. https://doi.org/10.1021/jf902264y.

Hernández-Ledesma, B., I. Recio, and L. Amigo. 2008. $\beta$-lactoglobulin as a source of bioactive peptides. Amino Acids 35:257-265. https: //doi.org/10.1007/s00726-007-0585-1.

Hills, B. P., S. F. Takacs, and P. S. Belton. 1990. A new interpretation of proton NMR relaxation time measurements of water in food. Food Chem. 37:95-111. https://doi.org/10.1016/0308 -8146(90)90084-H.

Hinrichs, R., J. Götz, M. Noll, A. Wolfschoon, H. Eibel, and H. Weisser. 2004. Characterisation of different treated whey protein concentrates by means of low-resolution nuclear magnetic resonance. Int. Dairy J. 14:817-827. https://doi.org/10.1016/j.idairyj.2004.02 .003 .

Hoffmann, M. A., and P. J. van Mil. 1997. Heat-induced aggregation of $\beta$-lactoglobulin: Role of the free thiol group and disulfide bonds. J. Agric. Food Chem. 45:2942-2948. https://doi.org/10 $.1021 /$ jf960789q.

Huppertz, T., and A. L. Kelly. 2006. Physical chemistry of milk fat globules. Pages 173-212 in Advanced Dairy Chemistry. Volume 2 Lipids. P. F. Fox and P. L. H. McSweeney, ed. Springer, Boston, MA.

International Organization for Standardization (ISO). 2013. Milk and milk products - Determination of alkaline phosphatase activity Part 1: Fluorimetric method for milk and milk-based drinks (ISO 11816-1:2013). International Organization for Standardization, Geneva, Switzerland.

Juarez, M., and M. Ramos. 2003. SHEEP | Milk. Pages 5198-5205 in Encyclopedia of Food Sciences and Nutrition (Second Edition). B. Caballero, ed. Academic Press, Cambridge, MA.

Lambelet, P., R. Berrocal, and F. Ducret. 1989. Low-resolution NMR spectroscopy: A tool to study protein denaturation: I. Application to diamagnetic whey proteins. J. Dairy Res. 56:211-222. https:// doi.org/10.1017/S0022029900026431.

Lambelet, P., R. Berrocal, and F. Renevey. 1992. Low-field nuclear magnetic resonance relaxation study of thermal effects on milk proteins. J. Dairy Res. 59:517-526. https://doi.org/10.1017/ S0022029900027187.

Le Dean, A., F. Mariette, and M. Marin. 2004. ${ }^{1}$ H Nuclear Magnetic Resonance relaxometry study of water state in milk protein mixtures. J. Agric. Food Chem. 52:5449-5455. https://doi.org/10 $.1021 /$ jf030777m.

Mariette, F., C. Tellier, G. Brulé, and P. Marchal. 1993. Multinuclear NMR study of the $\mathrm{pH}$ dependent water state in skim milk and caseinate solutions. J. Dairy Sci. 60:175-188. https://doi.org/10 $.1017 /$ S0022029900027497. 
Marth, E. H. 1978. Chapter 19, Chemical methods. Pages 237-246 in Standard Methods for the Examination of Dairy Products. 14th ed. American Public Health Association, Springfield, VA.

Mendia, C., F. C. Ibanez, P. Torre, and Y. Barcina. 1999. Effect of pasteurization on the sensory characteristics of a ewe's-milk cheese. J. Sens. Stud. 14:415-424. https://doi.org/10.1111/j.1745 $-459 X .1999 . t b 00125 . x$.

Moatsou, G. 2010. Indigenous enzymatic activities in ovine and caprine milks. Int. J. Dairy Technol. 63:16-31. https://doi.org/10 $.1111 /$ j.1471-0307.2009.00552.x.

Morales, F. J., C. Romero, and S. Jiménez Pérez. 2000. Characterization of industrial processed milk by analysis of heat-induced changes. Int. J. Food Sci. Technol. 35:193-200. https://doi.org/10 .1046/j.1365-2621.2000.00334.x.

Mulas, G., T. Roggio, S. Uzzau, and R. Anedda. 2013. A new magnetic resonance imaging approach for discriminating Sardinian sheep milk cheese made from heat-treated or raw milk. J. Dairy Sci. 96:7393-7403. https://doi.org/10.3168/jds.2013-6607.

Piga, C., P. P. Urgeghe, G. Piredda, M. F. Scintu, R. Di Salvo, and G. Sanna. 2013. Thermal inactivation and variability of $\gamma$-glutamyltransferase and $\alpha$-L-fucosidase enzymatic activity in sheep milk. Lebensm. Wiss. Technol. 54:152-156. https://doi.org/ 10.1016/j.lwt.2013.05.018

Pouliot, Y., M. Boulet, and P. Paquin. 1989. Experiments on the heatinduced salt balance changes in cow's milk. J. Dairy Res. 56:513519. https://doi.org/10.1017/S0022029900029009.

Provencher, S. W. 1982. Contin: A general-purpose constrained regularization program for inverting noisy linear algebraic and integral equations. Comput. Phys. Commun. 27:229-242. https://doi.org/ 10.1016/0010-4655(82)90174-6.

Rankin, S. A., A. Christiansen, W. Lee, D. S. Banavara, and A. LopezHernandez. 2010. Invited review: The application of alkaline phosphatase assays for the validation of milk product pasteurization. J. Dairy Sci. 93:5538-5551. https://doi.org/10.3168/jds.2010-3400.

Raynal-Ljutovac, K., Y. W. Park, F. Gaucheron, and S. Bouhallab. 2007. Heat stability and enzymatic modifications of goat and sheep milk. Small Rumin. Res. 68:207-220. https://doi.org/10 .1016/j.smallrumres.2006.09.006.

Scintu, M. F., E. Daga, and A. Ledda. 2000. Evaluation of spectrophotometric and fluorometric methods for alkaline phosphatase activity determination in ewe's milk. J. Food Prot. 63:1258-1261. https://doi.org/10.4315/0362-028X-63.9.1258.

Singh, H., and A. Waungana. 2001. Influence of heat treatment of milk on cheesemaking properties. Int. Dairy J. 11:543-551. https://doi org/10.1016/S0958-6946(01)00085-1.
Tellier, C., F. Mariette, J. P. Guillement, and P. Marchal. 1993. Evolution of water proton nuclear magnetic relaxation during milk coagulation and syneresis: Structural implications. J. Agric. Food Chem. 41:2259-2266. https://doi.org/10.1021/if00036a007.

van Dijk, H. J. M., and A. Hersevoort. 1992. The properties of casein micelles. 5. The determination of heat induced calcium phosphate precipitations in milk. Neth. Milk Dairy J. 46:69-76.

van Duynhoven, J., A. Voda, M. Witek, and H. Van As. 2010. TimeDomain NMR Applied to Food Products (Chapter 3). Annu. Rep. NMR Spectroscopy 69:145-197. https://doi.org/10.1016/S0066 $-4103(10) 69003-5$.

Vasbinder, A. J., and C. G. De Kruif. 2003. Casein-whey protein interactions in heated milk: the influence of pH. Int. Dairy J. 13:669677. https://doi.org/10.1016/S0958-6946(03)00120-1.

Walstra, P., T. J. Geurts, A. Noomen, A. Jellema, and M. A. J. S. van Boekel. 1999. Part II: Heat treatment. Pages 189-199 in Dairy Technology: Principles of Milk Properties and Processes. P. Walstra, T. J. Geurts, A. Noomen, A. Jellema, and M. A. J. S. van Boekel, ed. Marcel Dekker Inc., New York, NY.

Walstra, P., T. J. Geurts, P. Walstra, and J. T. Wouters. 2005. Dairy Science and Technology. CRC Press, Boca Raton, FL.

Wijayanti, H. B., N. Bansal, and H. C. Deeth. 2014. Stability of whey proteins during thermal processing: A review. Compr. Rev. Food Sci. Food Saf. 13:1235-1251. https://doi.org/10.1111/1541-4337 .12105 .

Ye, A., H. Singh, D. J. Oldfield, and S. Anema. 2004. Kinetics of heatinduced association of $\beta$-lactoglobulin and $\alpha$-lactalbumin with milk fat globule membrane in whole milk. Int. Dairy J. 14:389-398. https://doi.org/10.1016/j.idairyj.2003.09.004.

\section{ORCIDS}

E. Curti ๑ https://orcid.org/0000-0003-1941-1195

A. Pardu (๑) https://orcid.org/0000-0003-2107-2997

R. Melis @ https://orcid.org/0000-0003-4854-9011

M. Pes (ㄴ) https://orcid.org/0000-0001-5858-5695

A. Pirisi (1) https://orcid.org/0000-0001-8993-8406

R. Anedda ๑ https://orcid.org/0000-0003-1235-5821 